\title{
Differences in Unintended Pregnancy, Contraceptive Use and Abortion by HIV Status Among Women In Nigeria and Zambia
}

\section{By Akinrinola \\ Bankole, Sarah \\ Keogh, Odunayo \\ Akinyemi, \\ Kumbutso \\ Dzekedzeke, \\ Olutosin Awolude \\ and Isaac Adewole}

Akinrinola Bankole is director of international research and Sarah Keogh is senior research associate, both at the Guttmacher Institute, New York. Odunayo Akinyemi is lecturer, Department of Epidemiology and Medical

Statistics; Olutosin Awolude is consultant and lecturer, Department of Obstetrics and Gynaecology; and Isaac Adewole is

vice-chancellor and professor, Department of Obstetrics and Gynaecology-all at the University

of Ibadan, Nigeria. Kumbutso

Dzekedzeke is independent consultant, Lusaka, Zambia.

\begin{abstract}
CONTEXT: Sub-Saharan Africa is burdened by high rates of unintended pregnancy and HIV. Yet little is known about the relationship between these two health risks in the region. Understanding the associations between HIV status and pregnancy decision making may benefit strategies to reduce unintended pregnancy.
\end{abstract}

METHODS: In 2009-2010, household-based surveys of 1,256 women in Nigeria and 1,280 women in Zambia collected information on social and demographic characteristics, unintended pregnancy, contraceptive use, abortion and self-reported HIV status. Multivariate models were used to examine the association of reported HIV status with unintended pregnancy and abortion in the five years preceding the survey and with contraceptive use at the time of conception.

RESULTS: HIV-positive and HIV-negative women did not differ in their odds of unintended pregnancy or of having an abortion. However, HIV-positive women were more likely than HIV-negative women to have been using a contraceptive at the time their unintended pregnancy was conceived (odds ratio, 3.2). Women who did not know their HIV status were less likely than HIV-negative women to report an unintended pregnancy (0.6). However, they were also less likely than HIV-negative women to have been using a contraceptive at the time of conception (0.5).

CONCLUSION: HIV-positive women may be making greater efforts than HIV-negative women to prevent unintended pregnancy, but with less success. Efforts should be made to improve access to effective contraceptive methods and counseling for all women, and for HIV-positive women in particular.

International Perspectives on Sexual and Reproductive Health, 2014, 40(1):28-38, doi: 10.1363/4002814

With only $22 \%$ of married women currently using modern contraceptive methods, Sub-Saharan Africa has the lowest contraceptive prevalence ${ }^{1}$ and the highest level of unmet need for contraception of all world regions. ${ }^{2}$ This low contraceptive use has contributed to the high rate of unintended pregnancy in the region. Unintended pregnancies are more likely than intended pregnancies to end in negative health outcomes, including low birth weight, infant and child mortality, and maternal morbidity and mortality. ${ }^{3}$ In Sub-Saharan Africa, an estimated 39\% of pregnancies are unintended, and 33\% of these end in abortion, most of which are unsafe. 4,5

In addition, HIV infection is widespread in Africa; in parts of southern Africa, prevalence among adults is higher than $20 \%{ }^{6}$ The HIV epidemic is having a profound and complex effect on reproductive behavior in Africa. A desire for fewer children among HIV-positive women than among HIV-negative women or women of unknown status has been documented both in cross-sectional studies ${ }^{7-12}$ and in longitudinal studies that followed women after they received their HIV diagnosis. ${ }^{13-16}$ Women's decreased desire for additional children after learning they are HIVpositive has been explained by concerns over motherto-child transmission and leaving orphans, as well as by perceived health risks involved in pregnancy for an HIVpositive woman. ${ }^{8,17}$
However, HIV-positive women's desire for fewer children often does not translate into lower pregnancy rates: Studies have found that HIV-positive women are as likely as, ${ }^{13,15}$ if not more likely than, ${ }^{14}$ HIV-negative women to get pregnant. Nor is a desire for fewer children always associated with higher contraceptive use among HIVpositive women. Although this was the case in some studies, ${ }^{9,18}$ others found that contraceptive use was similar or lower among HIV-positive women than among their HIVnegative counterparts. ${ }^{12,19}$ Contraceptive decisions add another dimension to reproductive choices-HIV-positive women have to navigate specific risks related to their status, such as potential interactions between contraceptives, HIV and antiretroviral drugs, or having to explain the need for contraception to a partner. ${ }^{8}$ Considerations of abortion further complicate reproductive decisions for HIV-positive women in Africa, as they must weigh the often heavy stigma and high risk associated with a clandestine abortion against the stigma of continuing a pregnancy while HIVpositive. ${ }^{20}$ Qualitative studies have helped to shed light on these conflicting pressures. ${ }^{17,21-23}$ This "double bind," as Ingram and Hutchinson have called it, ${ }^{24}$ helps explain why the concept of pregnancy intendedness may be particularly problematic for people living with HIV.

Now, advances in antiretroviral therapy and prevention of mother-to-child transmission are changing the face of 
the epidemic in Sub-Saharan Africa, enabling HIV-positive individuals to live longer lives and have healthy families, and adding further complexity to the associations between HIV status and reproductive behavior. Studies from SubSaharan Africa have found that HIV-positive women on antiretroviral therapy desire more children ${ }^{25,26}$ and have higher pregnancy rates ${ }^{27,28}$ than HIV-positive women not on antiretroviral therapy, and that these associations tend to grow stronger with women's improved health and increased time on antiretroviral therapy. ${ }^{29-32}$ However, individuals on antiretroviral therapy still have high rates of unintended pregnancy. 33,34

Compared with intended pregnancies, unintended pregnancies are associated with greater health risks for both mother and baby, and these risks are magnified when the woman is HIV-positive. Therefore, understanding the relationship between HIV, unintended pregnancy and contraceptive use is a key element in developing programs and services that will enable HIV-positive individuals to achieve their reproductive goals. There is very little research looking specifically at the associations between HIV status and women's experience of unintended pregnancy, or their strategies to prevent it. One study examined the determinants of unintended pregnancy in HIVpositive adolescents in Kenya, ${ }^{35}$ but to our knowledge, none have compared HIV-positive and HIV-negative women, or looked at contraceptive use at the time an unintended pregnancy was conceived.

Also, few studies have examined the associations between HIV status and women's decision to obtain an abortion in the event of an unintended pregnancy. For many women in Africa, abortion decision making is difficult, because of widespread legal restrictions, social stigma, difficulties of access and provider bias. ${ }^{22,36}$ In addition, HIVpositive women must consider the risk of mother-to-child transmission and HIV-related health risks to the mother during pregnancy. 37,38

Although associations between HIV status and reproductive behavior have been widely documented in Africa, only a small proportion of the population actually know their status. The vast majority have never been tested, or if tested, did not get their results. In a multicountry analysis of recent Demographic and Health Survey (DHS) data from 29 countries in Sub-Saharan Africa, on average, only $29 \%$ of women had ever been tested for HIV. This figure is even lower for men (17\%), because many women are tested for HIV on an opt-out basis during antenatal care. ${ }^{39}$ Not knowing one's HIV status is associated with uncertainty regarding future life, relationships and childbearing, and may influence reproductive preferences and behaviors. For instance, suspicion and fear of HIV infection have been shown to affect childbearing intentions in individuals who do not know their status. ${ }^{16,40,41}$ These individuals also have a different social and demographic profile than those who know their status: The DHS analysis of 29 countries showed that the uptake of HIV testing was higher among women in urban areas than in rural areas, among women aged 20-34 than among younger and older women, and among women with higher education than among those with less education. ${ }^{39}$ Although these differences are usually controlled for in analyses, they suggest that there may be differences in other characteristics between women who know their status and those who don't. Understanding how this large group of women of unknown HIV status differs from its counterpart of known status with regard to unintended pregnancy, contraceptive use and abortion would help identify ways to best meet the reproductive needs of these women, and could also help to develop evidence-based HIV testing programs.

This article uses data from representative, communitybased surveys of women in Nigeria and Zambia to examine the association of HIV status with unintended pregnancy, contraceptive use at the time of conception and abortion. Specific research questions include: Does women's likelihood of experiencing an unintended pregnancy, and their efforts to prevent it through contraceptive use or to resolve it through an abortion, differ by HIV status? How do women who do not know their status differ from those who do in these reproductive outcomes? Because the primary focus of the article is unintended pregnancy and the strategies used to address it, we examine contraceptive use and abortion in the context of respondents' recent experiences of unintended pregnancy.

We chose to study Nigeria and Zambia, two countries from the western and southern subregions of Sub-Saharan Africa, respectively, because of their different HIV, fertility preference and abortion contexts. Nigeria has a relatively low HIV prevalence of $4 \%$, but because of its huge population is home to the second-largest number of people living with HIV after South Africa. ${ }^{6}$ Nigerian women have a desired family size of 6.1 children. ${ }^{42}$ Only $11 \%$ of women are currently using a modern contraceptive method, and $20 \%$ have an unmet need for contraception. According to the 2008 DHS, $7 \%$ of births are reported as mistimed, while $4 \%$ are unwanted. ${ }^{42}$ About $20-28 \%$ of women of reproductive age have ever had an unwanted pregnancy, and more than half of these reported having attempted to terminate it, ${ }^{43,44}$ despite legislation permitting abortion only to save a woman's life ${ }^{45}$ and the high risk of experiencing complications. ${ }^{46}$

Zambia has a higher HIV prevalence (13\%). ${ }^{6}$ Women desire a mean of 4.6 children. ${ }^{47}$ Modern contraceptive methods are used by $25 \%$ of women of reproductive age, but unmet need remains high, at $27 \%$. About $26 \%$ of births are mistimed, and $16 \%$ are not wanted at all. ${ }^{47}$ An estimated two-thirds of unwanted pregnancies end in induced abortion. ${ }^{48}$ Although abortion is permitted on health and socioeconomic grounds, in practice, women are often unable to obtain safe abortions because of the numerous required authorizations and other logistic barriers; ${ }^{49}$ as a result, many such women resort to unsafe abortion.

These two countries provide contrasting contexts within which to examine the association between HIV, unintended pregnancy and women's strategies to address it-specifi- 
TABLE 1. Percentage distribution of women aged 18-49, by selected characteristics, Nigeria and Zambia, 2009-2010

\begin{tabular}{|lccc} 
Characteristic & $\begin{array}{l}\text { All } \\
(\mathrm{N}=2,204)\end{array}$ & $\begin{array}{l}\text { Nigeria } \\
(\mathrm{N}=1,008)\end{array}$ & $\begin{array}{l}\text { Zambia } \\
(\mathrm{N}=1,196)\end{array}$ \\
\hline Age & & & \\
$18-24$ & 26.6 & 26.1 & 27.1 \\
$25-34$ & 40.2 & 40.6 & 39.9 \\
$35-49$ & 33.2 & 33.3 & 33.0 \\
& & & \\
Residence & 53.1 & 63.3 & 44.6 \\
Urban & 46.9 & 36.7 & 55.4 \\
Rural & & & \\
Highest level of school attended & & \\
None & 15.0 & 21.8 & 9.2 \\
Primary & 38.1 & 19.9 & 53.3 \\
$\geq$ secondary & 47.0 & 58.2 & 37.5 \\
& & & \\
Union status & & & \\
Married or cohabiting & 71.5 & 71.6 & 71.3 \\
Not in union & 28.5 & 28.4 & 28.7 \\
No. of living children & & & \\
0 & 19.6 & 28.4 & 12.2 \\
1-2 & 29.7 & 29.0 & 30.4 \\
3-4 & 27.0 & 24.7 & 28.9 \\
$\geq 5$ & 23.7 & 18.0 & 28.5 \\
Total & & & \\
& 100.0 & 100.0 & 100.0
\end{tabular}

cally, contraceptive use at the time of conception and experience of abortion following unintended pregnancy.

\section{DATA AND METHODS}

Data for this study come from 2009-2010 householdbased surveys in Nigeria and Zambia that were part of a larger study of how women and men achieve their reproductive goals while living with or trying to prevent infection with HIV. The surveys were conducted in three provinces in Zambia (Lusaka, Northern and Southern provinces) and four states in Nigeria (Benue, Enugu, Kaduna and Lagos). Although the samples are not nationally representative (they are not probability samples of the whole country), they were selected from across each country to ensure a good representation of regions with varying HIV prevalence and fertility levels. The study protocols were approved by the institutional review boards of the Guttmacher Institute and the University of Ibadan/ University College Hospital, Nigeria, and by the University of Zambia Biomedical Research Ethics Committee.

In Nigeria, one rural and one urban local government area were randomly selected from each of the four selected states. The local government areas in each state were ordered according to the population figures from the 2006 census. Ten and 20 enumeration areas, respectively, were then systematically selected from the rural and urban local government areas in keeping with the rural-urban population ratios of the local government areas. In the selected enumeration area, $10 \%$ of households were systematically selected for interview.

The Zambian sample was based on the sampling frame from the 2007 Zambia DHS. ${ }^{47}$ The number of households selected was determined by the ratio of households to completed interviews of the population aged 15 years and older observed in the 2007 DHS. To yield the target sample size, 60 enumeration areas were selected from the three chosen provinces by equal probability systematic sampling, including 38 rural and 22 urban enumeration areas. The total sample was allocated to the provinces proportional to its projected 2009 population, distributed by rural-urban residence, obtained from the Central Statistical Office..$^{50}$

Data collection lasted from November 2009 to May 2010 in Nigeria and from October 2009 to February 2010 in Zambia. All women aged 18-49 and men aged 18-59 in selected households were interviewed by trained interviewers from the same province or state as the respondents. A total of 2,451 adults (1,256 women and 1,195 men) in Nigeria and 2,400 (1,280 women and 1,120 men) in Zambia were successfully interviewed, yielding response rates of $94 \%$ and $92 \%$, respectively. This article is based on data collected from women.

- Outcome variables. We examine three outcome variables. The first is experience of recent unintended pregnancy (in the five years prior to the survey). This information was obtained from women's responses to a series of questions to identify not only pregnancies that were unwanted by the woman at that time, but also pregnancies that she may have wanted but that her partner did not want, or that would have caused problems for her to keep. First, women were asked, "Have you ever been pregnant when you did not want to be?" Those who did not respond positively to this question were then asked, "Has there ever been any time when a pregnancy would have caused difficulties for you because of life circumstances or the opposition of others, even though you wanted the pregnancy?" This question, which has been used in other surveys, ${ }^{44,51,52}$ aimed to capture the complex nature of pregnancy decision

TABLE 2. Percentage distribution of respondents, by HIV status and selected reproductive health indicators, according to country

\begin{tabular}{|c|c|c|c|}
\hline Characteristic & $\begin{array}{l}\text { All } \\
(\mathrm{N}=2,204)\end{array}$ & $\begin{array}{l}\text { Nigeria } \\
(\mathrm{N}=1,008)\end{array}$ & $\begin{array}{l}\text { Zambia } \\
(\mathrm{N}=1,196)\end{array}$ \\
\hline \multicolumn{4}{|l|}{ HIV status } \\
\hline Known, positive & 4.6 & 2.5 & 6.4 \\
\hline Known, negative & 41.5 & 25.1 & 55.4 \\
\hline Unknown & 53.9 & 72.4 & 38.3 \\
\hline \multicolumn{4}{|c|}{$\begin{array}{l}\text { Had } \geq 1 \text { unintended pregnancy } \\
\text { in previous } 5 \text { yrs. }\end{array}$} \\
\hline Yes & 14.8 & 8.4 & 20.2 \\
\hline No & 85.2 & 91.6 & 79.8 \\
\hline \multicolumn{4}{|c|}{$\begin{array}{l}\text { Used contraceptive at the time of last } \\
\text { unintended pregnancy in previous } 5 \text { yrs. }\end{array}$} \\
\hline Yes & 34.9 & 23.5 & 38.8 \\
\hline No & 65.1 & 76.5 & 61.2 \\
\hline \multicolumn{4}{|c|}{ Had an abortion in previous 5 yrs. $\dagger$} \\
\hline Yes & 11.3 & 30.6 & 4.6 \\
\hline No & 88.7 & 69.4 & 95.5 \\
\hline Total & 100.0 & 100.0 & 100.0 \\
\hline
\end{tabular}

$+\mathrm{N}=327$ ( 85 in Nigeria and 242 in Zambia). 
making and the potential involvement of several people in these decisions. Women who responded positively to either question were asked to give the month and year of their last unintended pregnancy, or failing that, their age at that time. From this information, we created the recent unintended pregnancy variable, which had a value of 1 if a woman had experienced an unintended pregnancy in the last five years and 0 otherwise.

Women reporting at least one unintended pregnancy were asked a standard DHS question, "Were you using any method or doing something to delay or avoid getting pregnant at that time?" We restricted our analysis for this measure to women who had become pregnant unintentionally in the last five years. Our second outcome variable, use of contraceptives at the time of the last unintended pregnancy within the last five years, was created with a value of 1 if a woman had been using a modern or traditional contraceptive method or doing something to avoid getting pregnant at the time and 0 if she had not.

The final outcome variable is recent abortion experience (in the five years prior to the survey). All women who had had an unintended pregnancy were asked, "Have you ever been in a position when you or someone else has had to do something to end your pregnancy?" Those who answered "yes" were asked how many times they had done so and the last time this had happened. The variable was assigned a value of 1 if a woman had had an abortion in the five years before the survey and 0 if she had not.

- Independent variable. The key independent variable, HIV status, is based on self-reports from a series of questions beginning with "Have you ever been tested to see if you have the AIDS virus?" Those who said "yes" were further asked, "How long ago were you last tested for the AIDS virus?" and "Did you get the results of that test?" Those who responded affirmatively to this last question were then asked, "Would you tell me your HIV test results?" and given a note that read "Please know that I will keep this information confidential." In addition, because stigma associated with being HIV-positive may prevent an HIV-positive person from reporting her or his status in a face-to-face interview, we included a sealed envelope module in the survey. In this module, at the end of the face-to-face interview, we asked again about HIV status to enable respondents to answer confidentially by marking their responses on a sheet of paper, putting the paper in an envelope, sealing it and handing it over to the interviewer. From the responses to questions on HIV status in both of these approaches, the HIV status variable was created with three categories: HIVpositive, HIV-negative and unknown HIV status. * Women who reported being HIV-positive in either the face-to-face interview or the sealed envelope module were coded as being HIV-positive. Among respondents who had had an unintended pregnancy, the date of the most recent positive HIV test for which they obtained the results enabled us to identify some women who knew their positive status at the time they conceived; however, because we only asked about the date of the most recent test, if women had an
TABLE 3. Odds ratios from logistic regression analyses identifying associations of HIV status and women's characteristics with unintended pregnancy in the last five years, pooled sample

Characteristic

Model 1

Model 2

HIV status

Known, positive

Known, negative (ref)

Unknown

\subsection{6}

1.00

$0.51^{* *}$

1.00

1.00

Country

Nigeria

$0.40^{* *}$

$0.61 * *$

Zambia (ref)

1.00

$0.52^{* *}$

1.00

Interaction terms

Nigeria $x$ HIV-positive

0.89

Nigeria $x$ unknown HIV status $\quad 1.21$

0.79

Age

18-24 (ref)

25-34

35-49

$\begin{array}{ll}\text { na } & 1.00 \\ \text { na } & 0.57^{* *}\end{array}$

Residence

Urban

Rural (ref)

na

1.04

Highest level of school attended

None

Primary

zsecondary (ref)

na

na

na

$0.77+$

Union status

Married or cohabiting

Not in union (ref)

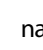

na

$0.64^{* *}$

No. of living children

0

$1-2$

3-4

$\geq 5$ (ref)

na $0.38^{* * *}$

na $0.51^{* *}$

na

1.00

$* * \mathrm{p} \leq .01 .+\mathrm{p} \leq .10$. Notes: ref=reference group. na=not applicable. Ns are unweighted.

unintended pregnancy before that date, we were not able to determine if they knew their status at the time of their unintended pregnancy.

- Demographic and socioeconomic variables. HIV-positive women, HIV-negative women and women who do not know their status likely differ in characteristics that may in turn affect associations between HIV status and reproductive outcomes. Therefore, the survey obtained data on social and demographic characteristics of the women, including age, rural-urban residence, highest level of education obtained, union status and number of living children; these characteristics were measured at the time of the survey.

\section{Analysis}

We present the distributions of social and demographic characteristics, HIV status and the three outcome variables-recent unintended pregnancy, contraceptive use at the time of the pregnancy and recent abortion experiencefor each country. To examine the association between HIV

*About $3 \%$ of respondents did not respond to the questions about HIV status; they were included in the group of women with unknown status. 


\begin{tabular}{|c|c|c|}
\hline Characteristic & Model 1 & Model 2 \\
\hline \multicolumn{3}{|l|}{ HIV status } \\
\hline Known, positive & $2.84 \dagger$ & $3.24^{*}$ \\
\hline Known, negative (ref) & 1.00 & 1.00 \\
\hline Unknown & $0.50^{*}$ & $0.46^{*}$ \\
\hline \multicolumn{3}{|l|}{ Country } \\
\hline Nigeria & 0.54 & 0.49 \\
\hline Zambia (ref) & 1.00 & 1.00 \\
\hline \multicolumn{3}{|l|}{ Interaction terms } \\
\hline Nigeria x HIV-positive & 0.93 & 0.40 \\
\hline Nigeria x unknown HIV status & 1.34 & 1.76 \\
\hline \multicolumn{3}{|l|}{ Age } \\
\hline $18-24$ (ref) & na & 1.00 \\
\hline $25-34$ & na & $2.37^{*}$ \\
\hline $35-49$ & na & 0.95 \\
\hline \multicolumn{3}{|l|}{ Residence } \\
\hline Urban & na & $0.58^{*}$ \\
\hline Rural (ref) & na & 1.00 \\
\hline \multicolumn{3}{|c|}{ Highest level of school attended } \\
\hline None & na & 0.48 \\
\hline Primary & na & 0.78 \\
\hline$\geq$ secondary (ref) & na & 1.00 \\
\hline \multicolumn{3}{|l|}{ Union status } \\
\hline Married or cohabiting & na & 1.32 \\
\hline Not in union (ref) & na & 1.00 \\
\hline \multicolumn{3}{|l|}{ No. of living children } \\
\hline 0 & na & 1.15 \\
\hline $1-2$ & na & 0.68 \\
\hline $3-4$ & na & 0.71 \\
\hline$\geq 5$ (ref) & na & 1.00 \\
\hline
\end{tabular}

status and each of the outcome variables, we employed multivariate logistic regression. For the multivariate analyses, we pooled the data for the two countries to have a data set with sizable numbers of HIV-positive women and women who had had abortions and included a control for country to ensure that differences in the associations between the two countries were accounted for. In model 1, we fitted a regression equation modeling the association of HIV status with each dependent variable, controlling for country and an interaction term for HIV status and country. In model 2, we explored whether HIV status is independently associated with the outcome variables, net of the effects of social and demographic characteristics. Statistical significance was examined at the .05 and .01 levels, using two-tailed tests. The analysis was performed in Stata 12 , using the svy command to account for survey design.

\section{RESULTS}

\section{Sample Characteristics}

About one-quarter of respondents were younger than 25 and one-third were 35 or older, with a similar distribution for Nigeria and Zambia (Table 1, page 30). The propor- tion of urban respondents was $53 \%$ overall $(63 \%$ in $\mathrm{Ni}$ geria and $45 \%$ in Zambia). More than half of the Nigerian respondents (58\%) had secondary or higher education, compared with $38 \%$ of Zambian respondents. Overall, almost $72 \%$ of respondents were in union. Among Nigerian women, $43 \%$ had three or more children, compared with $57 \%$ in Zambia.

Overall, about $5 \%$ of respondents reported being HIVpositive, while $42 \%$ said they were HIV-negative and 54\% reported not knowing their status (Table 2, page 30). In Zambia, $62 \%$ of women knew their HIV status, compared with $28 \%$ of their Nigerian counterparts. The proportion of women who reported being HIV-positive was twice as high among Zambians as among Nigerians (6\% vs. 3\%).

Overall, 15\% of women reported having experienced an unintended pregnancy in the last five years, with a higher proportion in Zambia than in Nigeria ( $20 \%$ vs. $8 \%$ ). About one-third of the women had been using a contraceptive method at the time of their last unintended pregnancy, with method use at conception higher in Zambia than in Nigeria (39\% vs. $24 \%$ ). Among women who reported having had an unintended pregnancy in the last five years, $11 \%$ reported having had an abortion, with a much higher proportion in Nigeria (31\%) than in Zambia (5\%).

\section{HIV Status and Unintended Pregnancy}

In a logistic regression controlling only for country, HIVpositive respondents did not differ significantly from their HIV-negative counterparts in their experience of unintended pregnancy in the last five years (Table 3, model 1, page 31). Respondents of unknown status were significantly less likely to have experienced an unintended pregnancy than HIV-negative respondents (odds ratio, 0.5).

Although Nigerian women had 60\% lower odds of reporting an unintended pregnancy than Zambian women, there were no significant interactions between country and HIV status, which indicates that the two countries displayed similar associations between HIV and unintended pregnancy and that it is appropriate to pool data for the two countries.

After controls for social and demographic characteristics were added, respondents of unknown HIV status still had significantly lower odds of experiencing unintended pregnancy than HIV-negative respondents (odds ratio, 0.6; Table 3, model 2). Odds of unintended pregnancy continued to be significantly lower for Nigerian women than for Zambian women (0.5). Other social and demographic characteristics were significantly associated with unintended pregnancy: Odds of experiencing an unintended pregnancy decreased with increasing age (from 0.6 to 0.2 ), were lower for women in union (0.6) and increased with number of living children (from 0.2 to 0.5 ).

\section{HIV Status and Method Use at Time of Conception}

In a logistic regression controlling only for country, the odds of having used a contraceptive method at the time the unintended pregnancy was conceived were nearly 
TABLE 5. Odds ratios from logistic regression analyses identifying associations of HIV status and women's characteristics with having had an abortion in the last five years, pooled sample

\begin{tabular}{|c|c|c|}
\hline Variable & Model 1 & Model 2 \\
\hline \multicolumn{3}{|l|}{ HIV status } \\
\hline Known, positive & 2.82 & 2.04 \\
\hline Known, negative (ref) & 1.00 & 1.00 \\
\hline Unknown & $4.02^{*}$ & $3.76+$ \\
\hline \multicolumn{3}{|l|}{ Country } \\
\hline Nigeria & $8.23^{* *}$ & $4.42 \dagger$ \\
\hline Zambia (ref) & 1.00 & 1.00 \\
\hline \multicolumn{3}{|l|}{ Interaction terms } \\
\hline Nigeria $x$ HIV-positive & 1.70 & 2.17 \\
\hline Nigeria $x$ unknown HIV status & 0.70 & 0.62 \\
\hline \multicolumn{3}{|l|}{ Age } \\
\hline $18-24$ (ref) & na & 1.00 \\
\hline $25-34$ & na & 1.04 \\
\hline $35-49$ & na & 1.57 \\
\hline \multicolumn{3}{|l|}{ Residence } \\
\hline Urban & na & $2.89^{*}$ \\
\hline Rural (ref) & na & 1.00 \\
\hline \multicolumn{3}{|c|}{ Highest level of school attended } \\
\hline None & na & 0.77 \\
\hline Primary & na & 0.75 \\
\hline$\geq$ secondary (ref) & na & 1.00 \\
\hline \multicolumn{3}{|l|}{ Union status } \\
\hline Married or cohabiting & na & 0.82 \\
\hline Not in union (ref) & na & 1.00 \\
\hline \multicolumn{3}{|l|}{ No. of living children } \\
\hline 0 & na & $11.35^{* *}$ \\
\hline $1-2$ & na & 1.91 \\
\hline $3-4$ & na & 2.31 \\
\hline$\geq 5$ (ref) & na & 1.00 \\
\hline
\end{tabular}

${ }^{*} p \leq .05 .{ }^{* *} p \leq .01 .+p \leq .10$. Notes: Both models were estimated for the 327 women who had had an unintended pregnancy in the last five years. ref=reference group. na=not applicable. Ns are unweighted.

three times as high among HIV-positive respondents as among their HIV-negative counterparts, although the difference was only marginally significant (Table 4 , model 1 ). On the other hand, women who did not know their status were significantly less likely than HIV-negative women to have been using a method (odds ratio, 0.5 ). After adjusting for social and demographic characteristics, the magnitude of these associations increased: HIV-positive respondents were significantly more likely than HIV-negative respondents to have been using contraceptives (3.2, model 2), and respondents who did not know their status had lower odds than their HIV-negative counterparts of having been using a method (0.5). As in the analysis of unintended pregnancy, there was no significant interaction between country and HIV status.

Some social and demographic characteristics were significantly associated with contraceptive use in the second model: Respondents aged 25-34 had 2.4 times the odds of 18-24-year-olds of having used contraceptives at the time of their unintended conception, and urban women had significantly lower odds than rural women of having used a method (0.6).

\section{HIV Status and Abortion}

In a model controlling only for country, among women who had had an unintended pregnancy in the last five years, those who did not know their HIV status were significantly more likely than those who were HIV-negative to report having had an abortion (odds ratio, 4.0; Table 5 , model 1). The odds of having had an abortion among Nigerian women were more than eight times those among their Zambian counterparts. The interaction term for HIV status and country was not significant.

After controlling for social and demographic characteristics, the difference in the odds of abortion between respondents of unknown HIV status and their HIVnegative counterparts decreased and lost significance (Table 5, model 2). In addition, Nigerian women were no longer significantly more likely to have had an abortion than Zambian women. The odds of abortion differed significantly by only two characteristics of women. Urban women were more likely than rural women to report having resolved an unplanned pregnancy with an abortion (odds ratio, 2.9), and women with no living children were more likely to have had an abortion than were women who had had five or more children (11.4).

\section{DISCUSSION}

Nigeria and Zambia represent contrasting contexts within which to examine the association of HIV status with unintended pregnancy, contraceptive use and abortion. Although women who did not know their HIV status were less likely than HIV-negative respondents to have had a recent unintended pregnancy, they were also less likely to have been using contraceptives at the time of unintended pregnancy. These patterns could be attributable to greater ambivalence toward pregnancy among women who did not know their status: They may be less likely to report a pregnancy as unintended, and the lower contraceptive use among those who did so may suggest they were less concerned about getting pregnant at the time. Those who did not know their HIV status were also more likely to terminate an unintended pregnancy than HIV-negative women. It is possible that instead of acting to prevent an unintended pregnancy, women of unknown HIV status react to such a pregnancy by rationalizing it as intended or by having an abortion. The two above-mentioned hypotheses-greater ambivalence toward pregnancy and reactive rather than proactive behavior-are both consistent with the women's lack of knowledge of their HIV status, because getting an HIV test, like using contraceptives and planning pregnancies, demonstrates proactive behavior.

Because the majority of HIV-negative respondents already knew their status at the time of their unintended pregnancy (while the rest may or may not have known it), these associations may have a causal element (for example, knowledge of HIV-negative status may reduce ambivalence about pregnancy). However, it is just as plausible that these associations are not causal, and that other characteristics are influencing both HIV testing and pregnancy 
planning behaviors. For example, women who know their status might attend health facilities more regularly and engage in more preventive behaviors, including HIV testing and greater use of contraceptives, than those who do not know their status. These different health-seeking behaviors would hold regardless of whether the HIV-negative respondents already knew their status at the time of their unintended pregnancy. A study in South Africa found that individuals who attended health facilities more often were more likely to get an HIV test. ${ }^{53}$ Also, women who do not know their status may consider themselves at lower risk of HIV, which may make them less likely to seek testing, and also less likely than those who know their status to use contraceptives for prevention of STI transmission or pregnancy.

The higher contraceptive use among respondents who knew their HIV status at the time of their unintended pregnancy may have been due to exposure to healthrelated messages during HIV counseling. This suggests the importance of promoting HIV testing to achieve healthy reproductive outcomes. The fact that $38 \%$ of respondents in Zambia, and more than $72 \%$ in Nigeria, reported not knowing their HIV status at interview emphasizes the need for greater promotion of HIV testing. Although optout HIV testing is offered as part of antenatal care in Zambia, many young women at risk of HIV have not yet been pregnant; these women need to be targeted with other interventions to increase testing.

An alternative explanation for the lower unintended pregnancy rates among women of unknown status is that they may be better contraceptive users. Their contraceptive failure rates may be lower than in HIV-negative women, so that only a small proportion of these effective contraceptive users end up with unintended pregnancies. With HIV testing being routinely offered during antenatal care, women who do get pregnant may be more likely to get tested and therefore know their status, which would explain why unintended pregnancy appears to be higher among women who know their status. This would help explain the higher unintended pregnancy rate among HIV-negative women compared with those of unknown status. If this is indeed the case and the high contraceptive prevalence at the time of unintended pregnancy signals high contraceptive failure, women need contraceptive services that integrate HIV testing, so that they can obtain a comprehensive package of preventive services rather than having to wait until they become unintentionally pregnant to be offered an HIV test.

There were few differences in reproductive outcomes between HIV-positive and HIV-negative respondents. The two groups had similar odds of experiencing an unintended pregnancy in the last five years. However, HIV-positive women had higher contraceptive use at the time of unintended pregnancy than their HIV-negative counterparts, as has been found in previous studies, ${ }^{9,18}$ perhaps because of a stronger desire to avoid a pregnancy. ${ }^{10}$ In contrast, HIVnegative respondents may have been more ambivalent about their fertility desire, but their lower contraceptive use may not have translated into higher rates of unintended pregnancy because they were more likely to report their pregnancy as intended. . $^{15,54}$

But if HIV-positive women were more motivated to avoid an unintended pregnancy, why were they so unsuccessful at it, with odds of unintended pregnancy similar to those of their HIV-negative counterparts despite higher contraceptive use? It could be that HIV-positive and HIVnegative women were using contraceptives for different purposes, and that the greater contraceptive use reported by HIV-positive women was primarily to prevent STI transmission. If so, they would have been more likely to be using condoms than other methods that might be more effective at preventing pregnancy. This explanation could also apply to the minority of respondents who may not have known they were HIV-positive at the time of their unintended pregnancy; respondents who reported being HIV-positive at the time of the survey may already have been using condoms at the time they conceived, because they considered themselves at higher risk for HIV or STIs. An earlier study from Zambia also reported higher use of contraceptives, particularly condoms, among HIV-positive women than among their HIV-negative counterparts. ${ }^{55}$

Alternatively, HIV-positive women who knew their status at the time of their unintended pregnancy may have been using contraceptive methods for pregnancy prevention, but less consistently and correctly than HIV-negative women, perhaps out of mistaken fear that using hormonal contraceptives on a regular basis could worsen their health status, as found in previous research. ${ }^{8}$ Thus, HIV-negative women may experience lower contraceptive failure rates, and therefore appear to have lower contraceptive use at the time of unintended pregnancy.

These results highlight two patterns. On the one hand, HIV infection may be associated with lower wanted fertility and higher contraceptive use. This association lends support to previous studies. ${ }^{10,11,56}$ Although this article examines associations rather than causal relationships, it is noteworthy that the majority (65\%) of respondents of known status who had an unintended pregnancy had had their last HIV test prior to their unintended pregnancy, while a further $24 \%$ had had it in the same year as their pregnancy. It is therefore plausible that test results could be influencing the likelihood of experiencing an unintended pregnancy for most of the respondents. However, our data cannot ascertain whether these relationship operate through a direct causal pathway (plausible for the majority who knew their status at the time of the pregnancy), or indirectly through other sexual behavior characteristics influencing both HIV risk and reproductive behavior. Regardless, the fact that increased contraceptive use was not coupled with lower odds of unintended pregnancy in HIVpositive women highlights significant failures in meeting their higher need for avoiding pregnancy.

This study has some limitations. Given that HIV status was self-reported, because of the stigma associated with 
being HIV-positive, we expect HIV-positive status to be underreported. Thus, while the survey yielded a $6 \%$ prevalence rate in Zambia, the rate based on HIV biomarkers obtained by the DHS in 2007 was 15\%, more than twice the self-reported rate. Similarly, for Nigeria, the HIV prevalence in 2010 based on data from sentinel surveys among antenatal clients was $4 \%$, compared with the 3\% reported in our survey. ${ }^{57}$ Therefore, it is likely that HIV-positive status was underreported and some HIV-positive individuals were misclassified as not knowing their status or as HIVnegative. This could have affected the associations between HIV status and the outcome variables. However, the fact that respondents of unknown status appeared to have outcomes notably different from those of HIV-positive women suggests that the overlap between the two groups was not sizable.

Also, abortion is likely to be underreported in face-toface surveys. This may have been more of a problem in Zambia. The proportion of women who reported having an abortion was higher in Nigeria, indicating more complete reporting than in a previous study. ${ }^{58}$ Because there is no evidence that abortion reporting differs by HIV status, underreporting of abortion is not likely to have biased the results. In addition, some unintended pregnancies may be misreported as intended because of postchildbearing rationalization. However, comparison with national statistics on unintended births does not suggest that this was a major issue in our sample. ${ }^{42,47}$ Finally, because social and demographic information was collected at the time of the survey, such characteristics as union status could have changed since the conception of the unintended pregnancy. Restricting the study time to the last five years should have minimized this issue. Although we endeavored to control for differences in social and demographic characteristics between HIV-positive and HIV-negative respondents, it is possible that differences between the two groups in other unmeasured characteristics affected the results. However, the existing literature does not point to any critical differences between HIV-positive and HIV-negative women that were not accounted for in the models.

In light of the greater health risks involved in an HIVpositive woman's pregnancy for both mother and baby, it is all the more important that HIV-positive women receive the antenatal and postnatal care necessary for healthy outcomes. Furthermore, given that women with unintended pregnancies are less likely to obtain adequate antenatal care, ${ }^{3}$ concerted efforts should be made to reduce rates of unintended pregnancy through improved access to effective contraceptive methods and counseling, particularly for HIV-positive women. To this end, it is important to further the integration of HIV and family planning services. The current policy, whereby funds from the President's Emergency Plan for AIDS Relief (PEPFAR) can be used to provide contraceptive counseling but not to procure contraceptive commodities, needs to be reviewed because this hinders efforts toward service integration. Several studies have found that HIV-positive women would prefer to re- ceive family planning methods from their HIV care providers rather than to have to disclose their status to yet another person. ${ }^{59,60}$

Further research should investigate why HIV-positive women have such high rates of contraceptive failure ending in unintended pregnancy; reasons may be different for those who knew their status at the time of their pregnancy and for those who did not. If contraceptive use by HIVpositive women is primarily aimed at preventing STI and HIV transmission, efforts should be made to increase the effectiveness of contraceptives in preventing pregnancy. Concurrent use of hormonal methods and condoms (dual method use) can be promoted as a way to maximize protection against HIV, other STIs and pregnancy. However, dual method use has been found to be very unpopular in Africa, where negotiating the use of even one method with a partner is difficult. ${ }^{61,62}$ Faced with a choice between discreet, highly effective hormonal methods, on the one hand, and difficult-to-negotiate and reportedly less effective condoms on the other, women concerned primarily with avoiding pregnancy will most often choose hormonal methods instead of condoms. ${ }^{62}$ One way to increase the popularity of condoms may be to emphasize that they play an important role in pregnancy prevention as well as in STI protection (if used consistently and correctly)-a function often sidelined in condom promotion efforts.

The fact that about two-thirds of respondents were not using contraceptives at the time of their unintended pregnancy indicates a high unmet need for contraception, particularly in Nigeria, where fewer than one-quarter of respondents were using contraceptives at the time they conceived. A better understanding of why women were not using contraceptives despite wanting to avoid a pregnancy can help develop policies to address this unmet need. This is particularly urgent in settings with high HIV prevalence, where having an unmet need often means also being exposed to the risk of HIV.

On the other hand, the considerable proportion of women who were using contraceptives at the time they got pregnant points to other shortcomings of family planning services in meeting the demand for effective contraception, in both Nigeria and Zambia. Potential weaknesses may include inadequate information, as well as failure of providers to recommend appropriate contraceptives, inadequate follow-up and contraceptive stock-outs (causing contraceptive discontinuation). The different contraceptive needs of HIV-positive and HIV-negative women call for tailored counseling on appropriate methods for these two groups. Further research can shed light on the most salient reasons why contraceptives failed to protect women against unwanted pregnancy, so that strategies can be devised to address these issues.

\section{REFERENCES}

1. United Nations, World Contraceptive Use 2011, New York: United Nations Department of Economic and Social Affairs, 2011.

2. Alkema L et al., National, regional and global rates and trends in contraceptive prevalence and unmet need for family planning between 
1990 and 2015: a systematic and comprehensive analysis, Lancet, 2013, 381(9878): 1642-1652

3. Singh A, Singh A and Mahapatra B, The consequences of unintended pregnancy for maternal and child health in rural India: evidence from prospective data, Maternal and Child Health Journal, 2013, 17(3):493-500.

4. Sedgh $\mathrm{G}$ et al., Induced abortion: incidence and trends worldwide from 1995 to 2008, Lancet, 2012, 379(9816):625-632.

5. Singh S, Sedgh G and Hussain R, Unintended pregnancy: worldwide levels, trends and outcomes, Studies in Family Planning, 2010, 4l(4):241-250

6. Joint United Nations Programme on HIV/AIDS (UNAIDS), World AIDS Day Report 2012, Geneva: UNAIDS, 2012.

7. Adair T, Unmet need for contraception among HIV-positive women in Lesotho and implications for mother-to-child transmission, Journal of Biosocial Science, 2009, 4l(2):269-278.

8. Baek C and Rutenberg N, Addressing the family planning needs of HIV-positive PMTCT clients: baseline findings from an operations research study, Horizon Research Update, Washington, DC: Population Council, 2005

9. Elul B et al., Pregnancy desires, and contraceptive knowledge and use among prevention of mother-to-child transmission clients in Rwanda, AIDS, 2009, 23(Suppl. 1):S19-S26.

10. Heys J et al., Fertility desires and infection with the HIV: results from a survey in rural Uganda, AIDS, 2009, 23(Suppl. 1):S37-S45.

11. Johnson KB et al., Fertility preferences and the need for contraception among women living with HIV: the basis for a joint action agenda, AIDS, 2009, 23(Suppl. 1):S7-S17.

12. Peltzer K, Chao LW and Dana P, Family planning among HIV positive and negative prevention of mother to child transmission (PMTCT) clients in a resource poor setting in South Africa, AIDS and Behavior, 2009, 13(5):973-979.

13. Brou $\mathrm{H}$ et al., Contraceptive practices and pregnancy incidence among women after being tested for HIV in Abidjan, Côte d'Ivoire, Revue d'Epidemiologie et de Sante Publique, 2009, 57(2):77-86 (in French).

14. Forsyth $\mathrm{AD}$ et al., HIV infection and pregnancy status among adults attending voluntary counseling and testing in 2 developing countries, American Journal of Public Health, 2002, 92(11):1795-1800.

15. Taulo $\mathrm{F}$ et al., Fertility intentions of HIV-1 infected and uninfected women in Malawi: a longitudinal study, AIDS and Behavior, 2009, 13(Suppl. 1):20-27.

16. Yeatman SE, The impact of HIV status and perceived status on fertility desires in rural Malawi, AIDS and Behavior, 2009, 13(Suppl. 1):12-19.

17. Nduna M and Farlane L, Women living with HIV in South Africa and their concerns about fertility, AIDS and Behavior, 2009, 13(Suppl. 1):62-65.

18. Obare $\mathrm{F}$ and Birungi $\mathrm{H}$, The limited effect of knowing they are HIVpositive on the sexual and reproductive experiences and intentions of infected adolescents in Uganda, Population Studies, 2010, 64(1):97104

19. Rutenberg $\mathrm{N}$ and Baek C, Field experiences integrating family planning into programs to prevent mother-to-child transmission of HIV, Studies in Family Planning, 2005, 36(3):235-245.

20. Orner P, de Bruyn M and Cooper D, 'It hurts, but I don't have a choice, I'm not working and I'm sick': decisions and experiences regarding abortion of women living with HIV in Cape Town, South Africa, Culture, Health \& Sexuality, 2011, 13(7):781-795.

21. Aka-Dago-Akribi $\mathrm{H}$ et al., Issues surrounding reproductive choice for women living with HIV in Abidjan, Cote d'Ivoire, Reproductive Health Matters, 1999, 7(13):20-29.

22. Cooper D et al., "Life is still going on": reproductive intentions among HIV-positive women and men in South Africa, Social Science E Medicine, 2007, 65(2):274-283.
23. Smith DJ and Mbakwem BC, Life projects and therapeutic itineraries: marriage, fertility and antiretroviral therapy in Nigeria, AIDS, 2007, 21(Suppl. 5):S37-S41

24. Ingram D and Hutchinson SA, Double binds and the reproductive and mothering experiences of HIV-positive women, Qualitative Health Research, 2000, 10(1):117-132

25. Cooper D et al., Fertility intentions and reproductive health care needs of people living with HIV in Cape Town, South Africa: implications for integrating reproductive health and HIV care services, AIDS and Behavior, 2009, 13(Suppl. 1):38-46.

26. Maier $\mathrm{M}$ et al., Antiretroviral therapy is associated with increased fertility desire, but not pregnancy or live birth, among HIV+ women in an early HIV treatment program in rural Uganda, AIDS and Behavior 2009, 13(Suppl. 1):28-37.

27. Makumbi FE et al., Associations between HIV antiretroviral therapy and the prevalence and incidence of pregnancy in Rakai, Uganda, AIDS Research and Treatment, 2011, 2011:519492.

28. Myer L et al., Impact of antiretroviral therapy on incidence of pregnancy among HIV-infected women in Sub-Saharan Africa: a cohort study, PLoS Medicine, 2010, 7(2):e1000229.

29. Bussmann $\mathrm{H}$ et al., Pregnancy rates and birth outcomes among women on efavirenz-containing highly active antiretroviral therapy in Botswana, Journal of Acquired Immune Deficiency Syndromes, 2007, 45(3):269-273.

30. Homsy J et al., Reproductive intentions and outcomes among women on antiretroviral therapy in rural Uganda: a prospective cohort study, PLoS ONE, 2009, 4(1):e4149.

31. Marcellin F et al., Desire for a child among HIV-infected women receiving antiretroviral therapy in Cameroon: results from the national survey EVAL (ANRS 12-116), AIDS Care, 2010, 22(4):441-451.

32. Myer L, Morroni $C$ and Rebe K, Prevalence and determinants of fertility intentions of HIV-infected women and men receiving antiretroviral therapy in South Africa, AIDS Patient Care and STDs, 2007, 21(4):278-285.

33. King R et al., 'Pregnancy comes accidentally-like it did with me': reproductive decisions among women on ART and their partners in rural Uganda, BMC Public Health, 2011, 11:530.

34. Schwartz SR et al., High incidence of unplanned pregnancy after antiretroviral therapy initiation: findings from a prospective cohort study in South Africa, PLoS ONE, 2012, 7(4):e36039.

35. Obare F, van der Kwaak A and Birungi H, Factors associated with unintended pregnancy, poor birth outcomes and post-partum contraceptive use among HIV-positive female adolescents in Kenya, BMC Women's Health, 2012, 12:34

36. Feldman R and Maposhere C, Safer sex and reproductive choice: findings from "Positive Women: Voices and Choices" in Zimbabwe, Reproductive Health Matters, 2003, 11(22):162-173.

37. de Bruyn M, Safe abortion for HIV-positive women with unwanted pregnancy: a reproductive right, Reproductive Health Matters, 2003, 11(22):152-161.

38. Orner P et al., A qualitative exploration of HIV-positive pregnant women's decision-making regarding abortion in Cape Town, South Africa, Journal of Social Aspects of HIV/AIDS Research Alliance, 2010, 7(2):44-51.

39. Staveteig $S$ et al., Demographic patterns of HIV testing uptake in Sub-Saharan Africa, DHS Comparative Reports, Calverton, MD, USA ICF International, 2013, No. 30.

40. Grieser $\mathrm{M}$ et al., Reproductive decision making and the HIV/ AIDS epidemic in Zimbabwe, Journal of Southern African Studies, 2001, 27(2):225-243

41. Rutenberg N, Biddlecom AE and Kaona F, Reproductive decisionmaking in the context of HIV and AIDS: a qualitative study in Ndola, Zambia, International Family Planning Perspectives, 2000, 26(3):124130

42. National Population Commission (NPC) and ICF Macro, Nigeria Demographic and Health Survey 2008, Abuja, Nigeria: NPC and ICF 
Macro, 2013.

43. Okonofua FE et al., Assessing the prevalence and determinants of unwanted pregnancy and induced abortion in Nigeria, Studies in Family Planning, 1999, 30(1):67-77.

44. Sedgh $\mathrm{G}$ et al., Unwanted pregnancy and associated factors among Nigerian women, International Family Planning Perspectives, 2006, 32(4):175-184

45. Sudhinaraset M, Reducing unsafe abortion in Nigeria, In Brief, New York: Guttmacher Institute, 2008, No. 3.

46. Bankole A et al., Unwanted Pregnancy and Induced Abortion in Nigeria: Causes and Consequences, New York: Guttmacher Institute, 2013.

47. Central Statistical Office (CSO) et al., Zambia Demographic and Health Survey 2007, Calverton, MD, USA: CSO and Macro International, 2009.

48. Webb D, Attitudes to 'Kaponya Mafumo': the terminators of pregnancy in urban Zambia, Health Policy and Planning, 2000, 15(2):186193.

49. Likwa RN, Biddlecom AE and Ball H, Unsafe Abortion in Zambia, New York: Guttmacher Institute, 2009.

50. CSO, 2000 Census of Population Projections Report, Lusaka, Zambia: CSO, 2003

51. Ghana Statistical Service (GSS), Ghana Health Service (GHS) and Macro International, Ghana Maternal Health Survey 2007, Calverton, MD, USA: GSS, GHS and Macro International, 2009.

52. Juarez F, Cabigon J and Singh S, Unwanted pregnancies in the Philippines: the route to induced abortion and health consequences, paper presented at the XXV International Union for the Scientific Study of Population International Population Conference, Tours, France, July 18-23, 2005

53. MacPhail $\mathrm{C}$ et al., Factors associated with HIV testing among sexually active South African youth aged 15-24 years, AIDS Care, 2009, 2l(4):456-467.

54. Keogh SC et al., The impact of antenatal HIV diagnosis on postpartum childbearing desires in northern Tanzania: a mixed methods study, Reproductive Health Matters, 2012, 20(39, Suppl):39-49.

55. Bankole A, Biddlecom AE and Dzekedzeke K, Women's and men's fertility preferences and contraceptive behaviors by HIV status in 10 Sub-Saharan African countries, AIDS Education and Prevention, 2011, 23(4):313-328

56. Lutalo $\mathrm{T}$ et al., Trends and determinants of contraceptive use in Rakai District, Uganda, 1995-98, Studies in Family Planning, 2000, 31(3):217-227.

57. Federal Ministry of Health, 2010 National HIV Seroprevalence Sentinel Survey, Abuja, Nigeria: Federal Ministry of Health, Nigeria, 2011.

58. Bankole A et al., Abortion-seeking behavior among Nigerian women, Journal of Biosocial Science, 2008, 40(2):247-268.

59. Asiimwe D et al., Study of the Integration of Family Planning and VCT/ PMTCT/ART Programs in Uganda, Arlington, VA, USA: U.S. Agency for International Development, 2005.

60. Orner P et al., Clients' perspectives on HIV/AIDS care and treat ment and reproductive health services in South Africa, AIDS Care, 2008, 20(10):1217-1223

61. Heffron R et al., A prospective study of contraceptive use among African women in HIV-1 serodiscordant partnerships, Sexually Transmitted Diseases, 2010, 37(10):621-628.

62. Kleinschmidt I et al., Dual protection in sexually active women, South African Medical Journal, 2003, 93(11):854-857.

\section{RESUMEN}

Contexto: En el África Subsahariana se dan altas tasas de embarazos no planeados y de VIH. Sin embargo, se sabe muy poco sobre la relación entre estos dos riesgos sanitarios en la región. Comprender las relaciones entre la condición de VIH y la toma de decisiones sobre el embarazo puede propiciar estrategias para reducir los embarazos no planeados.

Métodos: Entre 2009 y 2010, se recolectó información a través de encuestas aplicadas a hogares sobre características sociales y demográficas, embarazos no planeados, uso de anticonceptivos, aborto y condición autoreportada de VIH de 1,256 mujeres en Nigeria y 1,280 mujeres en Zambia. Se usaron modelos multivariados para examinar la relación entre la condición autoreportada de VIH, el embarazo no planeado y el aborto en los cinco años previos a la encuesta, así como con el uso de anticonceptivos en el momento de la concepción. Resultados: No hubo diferencia entre las mujeres VIH-positivas y las VIH-negativas respecto a las probabilidades de tener un embarazo no planeado o de tener un aborto. Sin embargo, las mujeres VIH-positivas mostraron una probabilidad mayor de haber estado usando anticonceptivos en el momento en el que su embarazo no planeado fue concebido (cociente de probabilidades 3.2) que las mujeres VIH-negativas. Las mujeres que no conocían su condición de VIH mostraron una probabilidad menor de reportar un embarazo no planeado (0.6) que las mujeres VIH-negativas. Sin embargo, también mostraron una probabilidad menor de haber estado usando anticonceptivos al momento de la concepción (0.5) que las mujeres VIHnegativas.

Conclusión: Es posible que las mujeres VIH-positivas estén haciendo mayores esfuerzos que las mujeres VIH-negativas para prevenir los embarazos no planeados, pero con menos éxito. Es necesario realizar esfuerzos para mejorar el acceso a métodos anticonceptivos efectivos y a consejería para todas las mujeres, y en particular para las mujeres VIH-positivas.

\section{RÉSUMÉ}

Contexte: L'Afrique subsaharienne souffre du fardeau de hauts taux de grossesse non planifiée et de VIH. La relation entre ces deux risques de santé dans la région n'est cependant guère documentée. Comprendre les associations entre l'état sérologique VIH et la décision de grossesse peut être utile aux stratégies de réduction des grossesses non planifiées.

Méthodes: En 2009-2010, des enquêtes de ménage menées auprès de 1.256 Nigérianes et 1.280 Zambiennes ont collecté une information sur les caractéristiques sociodémographiques, la grossesse non désirée, la pratique contraceptive, l'avortement et l'état sérologique autodéclaré. Des modèles multivariés ont servi à l'examen de l'association entre l'état sérologique déclaré, d'une part, et, d'autre part, la grossesse non planifiée et l'avortement durant les cinq années précédant l'enquête, et la pratique contraceptive au moment de la conception.

Résultats: Les femmes séropositives et séronégatives ne présentent aucune différence quant à la probabilité de grossesse non planifiée ou de recours à l'avortement. Celles séropositives paraissent cependant plus susceptibles d'avoir pratiqué la contraception au moment de la conception non planifiée $(\mathrm{OR}, 3,2)$. Les femmes qui ignoraient leur état sérologique sont moins susceptibles que celles séronégatives de déclarer une grossesse non planifiée $(0,6)$. Elles sont cependant moins susceptibles aussi que celles séronégatives d'avoir pratiqué la contraception au moment de la conception $(0,5)$. 
Conclusion: Il est possible que les femmes séropositives s'efforcent davantage de prévenir les grossesses non planifiées, mais avec moins de succès que celles séronégatives. Des efforts doivent être déployés pour améliorer l'accès aux méthodes contraceptives efficaces et au conseil pour toutes les femmes, séropositives en particulier.

\section{Acknowledgments}

The authors would like to thank Ann Biddlecom, Nyovani Madise and Monica Magadi for reviewing an earlier draft of this article and for their helpful comments. Funding for this research was provided by the Eunice Kennedy Shriver National Institute of Child Health and Human Development (R01 HD 058359) and the Consortium for Research on Unsafe Abortion in Africa (<http://www. abortionresearchconsortium.org/>) and its principal donor, the UK Department for International Development.

Author contact:abankole@guttmacher.org

\section{Acknowledgment to Reviewers}

The editors wish to express their appreciation to the following reviewers for their assistance in evaluating material for International Perspectives on Sexual and Reproductive Health in 2013:

Elizabeth Aahman

Victor Agadjanian

Salahuddin Ahmed

Keera Allendorf

Claire Bailey

Sushanta Banerjee

Sarah Barber

Janine Barden-O'Fallon

Joy Noel Baumgartner

Ayaga Bawah

Stan Becker

Davida Becker

Ann Biddlecom

Deborah Billings

Jeffrey Bingenheimer

Lisa Bohmer

Christine Bourey

John Casterline
Sanjukta Chaudhuri

John Cleland

Siân Curtis

Abhijit Das

Mai Do

Amir Erfani

Becca Feldman

Karen Hardee

Sarah Hayford

Altaf Hossain

Uche Isiugo-Abanihe

Shireen Jejeebhoy

Brooke Johnson

Heidi Johnston

Heidi Jones

Esther Kaggwa

Vladimiaa Kantorova
Ivy Kodzi

Joan Kraft

G. Anil Kumar

Lauren Lessard

Carol Levin

Catherine MacPhail

Paulina Makinwa-

Adebusoye

Shawn Malarcher

Heather Marlow

Cicely Marston

Catherine Mathews

Barbara Mensch

Suneeta Mittal

Ann Moore

Elizabeth Oliveras

Nadine Peacock
John Pile

Saumya RamaRao

Gazaleh Samandari

K.G. Santhya

Enid Schatz

Christie Sennott

Nasra Shah

Hari Singh

Heather Sipsma

Ilene Speizer

John Stanback

May Sudhinaraset

John Townsend

Michael Vlassoff

Darcy White

Mellissa Withers

Sara Yeatman 